\title{
Quality and year-round availability of water delivered by improved water points in rural Tanzania: effects on coverage
}

\author{
Alejandro Jiménez Fernández de Palencia ${ }^{\mathrm{a}, \mathrm{b}}$ and A. Pérez-Foguet ${ }^{\mathrm{b}}$ \\ ${ }^{a}$ Corresponding author. ONGAWA, C/Cristóbal Bordiú, 19-21. $4^{\circ}$ D. 28006 Madrid, Spain \\ E-mail: alejandrojfp@gmail.com \\ ${ }^{b}$ Research Group on Cooperation and Human Development (GRECDH), Institute of Sustainability, Universitat Politècnica de \\ Catalunya (UPC), Campus Nord, 08034 Barcelona, Spain
}

\begin{abstract}
This paper reports the findings of three water point mapping (WPM) studies carried out in three rural districts of Tanzania covering 3,363 water points. The methodology was designed to estimate the influence that consideration of the quality of the water supplied and the year-round functionality of each water point would have on each district's coverage figures. To this end, the study included measurements of basic quality parameters (692 analyses) and characterisation of the year-round continuity of service, in addition to the data collected in standard WPM campaigns. Both the quality and year-round continuity results were analysed in a disaggregated form by water point technology. The results show that $22 \%$ of the improved water points analysed had more than $10 \mathrm{CFU}$ (colony-forming units)/100 ml of water and $19 \%$ were seasonal. Moreover, water service coverage in the districts studied fell $40 \%$ on average when quality and year-round continuity were considered. There is a strong need to include these basic factors in the minimum standards to be delivered and monitored in rural areas. Simple and efficient methodologies for including quality and year-round continuity measurements in the information routines, such as the one presented here, are a necessary step to this end.
\end{abstract}

Keywords: Africa; Drinking water; Improved water points; Mapping; Rural areas; Sustainability; Tanzania; Water quality; Water supply

\section{Introduction}

The importance of safe water for disease prevention is widely recognised (Esrey et al., 1991; Fay et al., 2005; Fewtrell et al., 2005) and links between water quality and food safety have also been studied (Jawahar \& Ringler, 2009), but practical problems arise when attempts are made to define and monitor access to safe water. One major difficulty is the establishment of acceptable water quality 
parameters. These parameters vary from one country to the next, since the public institutions responsible for them are influenced by economic and political factors, as well as by their own environment (Reimann \& Banks, 2004). This has resulted, for instance, in higher arsenic tolerances in India and higher fluoride tolerances in Ethiopia and Tanzania. Another problem is the frequency of supervision that can actually be implemented. In general, smaller population centres receive less attention, since potential problems are considered to affect fewer people and resources are limited. This lack of priority ends up affecting the quality of the water delivered by small systems even in developed countries, where recent studies show that the microbiological quality of drinking water from small rural systems is much worse than that from large systems (Hunter et al., 2009a).

Recently, it has been argued in the development arena that tap water quality might not be so important (and thus not so important to measure) if users can treat their water at home using household water treatment (HWT) systems. Despite the potential of HWT to improve the quality of the water consumed, certain issues must be taken into account. First, the effects of HWT on health have not yet been sufficiently documented and acceptability, scalability and the feasibility of private sector involvement are still uncertain (Johnson et al., 2008; Luby et al., 2008; Schmidt \& Cairncross, 2009). Second, contrary to the norm in urban areas, willingness to pay in rural areas will not always be high enough to ensure that households invest in improving the quality of the water delivered (Vasquez et al., 2009; Ahmad et al., 2005) or that they self-treat water in a safe way (Kumar Biswas \& Mandal, 2010). Unconditional support for this approach would in fact shift the responsibility for the safety of the water to citizens themselves, which runs counter to the human rightsbased point of view (UN, 2002).

Additionally, the WHO/UNICEF Joint Monitoring Programme for Water Supply and Sanitation (JMP), responsible for measuring the fulfilment of the Millennium Development Goals (MDG) has likewise devoted little consideration to water quality. The indicator used by the JMP for Target 10 (halve the proportion of people without sustainable access to safe drinking water and basic sanitation by 2015) is the number of people using improved water sources (WHO/UNICEF, 2000, 2010a). Information is collected through general household surveys and national censuses. The assumption is that certain types of drinking water sources are likely to deliver drinking water of adequate quality for basic health needs. Although the updated versions of the surveys include two new questions about HWT (whether it is done and what method is used) (WHO, 2006), these questions are used to establish a baseline for HWT rather than to assess the quality of the water consumed.

The limits of measuring progress through technology-based indicators have been pointed out (Hunt, 2001; Sutton, 2008; Rietveld et al., 2009; Hunter et al., 2010; Masduqi et al., 2010) and a more sequential approach has been advocated (Bartram, 2008). Following its latest report, the JMP considers water piped into a dwelling, plot or yard from other improved water points to be a further step in the "water service ladder' (WHO/UNICEF, 2010a), but it still calculates access to safe, sustainable water in terms of access to improved water points.

The JMP piloted the introduction of quality tests in monitoring programmes through the Rapid Assessment of Drinking Water Quality (RADWQ) protocol, initially tested in six countries, mainly in 2004 and 2005. Most of the country reports have recently been published (WHO/UNICEF, 2010b, $\mathrm{c}, \mathrm{d}, \mathrm{e}, \mathrm{f}$ ) and show poor results with regard to the quality of the water delivered, especially for water that is not piped. However, the latest 2010 JMP report only briefly mentions the RADWQ results. It talks about the 'challenge of measuring water quality' to be addressed in water targets 'beyond 2015'. It states that quality should be 'measured or estimated in a cost-effective manner' and proposes water 
safety plans as the standard feature for ensuring sustainable access to safe drinking water (WHO/ UNICEF, 2010a).

The seasonality of water sources is another factor of growing importance in rural water supplies, especially given the current climate situation (Paavola, 2008). It is broadly accepted that the continuity of a drinking water service is crucial to ensuring the associated health benefits. Recent studies show that over the course of a few days of raw water consumption, the annual health benefits attributed to consumption of water from an improved supply are almost completely lost (Hunter et al., 2009b). Intermittent service is also associated with changes in pressure in distribution networks, which can lead to materials being drawn in through cracks in the pipes. This, in turn, can lead to secondary contamination of the water supply (Hunt, 2001). Despite these facts, the JMP does not consider the seasonality-related aspects of the service. The standard question 'What is the main source of drinking-water for members of your household?' already accepts the unreliability or intermittence of the reported source (WHO, 2006).

This paper addresses the relationship between access to improved water sources, the quality of the water delivered and the year-round continuity of water service. Our results are based on three field studies that assessed 3,363 water points in three rural districts of Tanzania-Same (2006), Kigoma (2008) and Kibondo (2010)-with a total population of around 1.1 million people. The districts surveyed have different climatic conditions and, thus, different technological patterns with regard to water access. Quality and year-round continuity results by water point category are presented and the effects on the figures of access to safe and sustainable water in the districts concerned are discussed. General data about implementation costs are provided to support the widespread promotion of the method in similar contexts. Complementarity with the water safety plan approach is also discussed. We conclude with the policy implications of the study.

\section{Materials and methods}

\subsection{Background: water point mapping and statistics used}

The methodology used for the field study has been called enhanced water point mapping (EWPM) and is described in Section 2.2. It is based on the water point mapping (WPM) activities carried out by WaterAid and other agencies in many countries in recent years (WaterAid, 2010). WPM can be defined as an 'exercise whereby the geographical positions of all improved water points in an area are gathered in addition to management, technical and demographical information. This information is collected using GPS and a questionnaire located at each water point. The data is entered into a geographical information system and then correlated with available demographic, administrative and physical data. The information is displayed using digital maps' (WaterAid, ODI, 2005). The methodology helps to define access indicators constructed from the lowest geographical level using the available data (Jiménez \& Pérez-Foguet, 2008) and is also useful for analysing the functionality of water points depending on the technology used (Jiménez \& Pérez-Foguet, 2011).

WPM uses three variables to define a water point: source type, water point type and extraction system. These three parameters help to determine the category of the water point. The level of service (public water points, yard or house connections) is not used to determine the category. In this study, water points were grouped into five categories based on these three variables, as defined in Table 1 . The 
Table 1. Water point (WP) categories defined for the study and sample sizes.

\begin{tabular}{|c|c|c|c|}
\hline \multirow[b]{2}{*}{ Category } & \multirow[b]{2}{*}{ Definition } & \multicolumn{2}{|l|}{ Sample } \\
\hline & & $\begin{array}{l}\text { Number of } \\
\text { WPs }\end{array}$ & $\begin{array}{l}\% \text { of } \\
\text { sample }\end{array}$ \\
\hline $\begin{array}{l}\text { Deep wells/boreholes } \\
\text { (BHs) with hand pump }\end{array}$ & $\begin{array}{l}\text { Deep wells (either hand-dug tube wells or BHs) providing water } \\
\text { through a hand pump }\end{array}$ & 196 & 5.8 \\
\hline $\begin{array}{l}\text { Shallow well with hand } \\
\text { pump }\end{array}$ & Shallow wells providing water through a hand pump & 266 & 7.9 \\
\hline Gravity-fed & All water points fed by gravity systems, regardless of source type & 2,495 & 74.2 \\
\hline Protected spring & Protected springs not feeding networks & 267 & 8.0 \\
\hline Other & $\begin{array}{l}\text { Improved wells not included in previous categories, rainwater } \\
\text { harvesting not feeding networks and any kind of pumping } \\
\text { system (motorised, solar, wind) }\end{array}$ & 139 & 4.1 \\
\hline Total & All categories & 3,363 & 100.0 \\
\hline
\end{tabular}

'gravity-fed' category (all water points fed by gravity networks, regardless of source type) was the largest, accounting for $74.2 \%$ of the water points. It was followed by 'protected springs' and 'shallow wells', each of which accounted for around $8 \%$ of the sample, and 'deep wells', accounting for 5.8\% of the sample. Finally, the category 'other', which encompassed quite a heterogeneous set of water points, including motorised pumping systems and rainwater-fed water points, accounted for a total of $4.1 \%$ of the sample. We acknowledge that establishing more categories could give a more precise picture of the results, but the sample size limited further splitting of the results. Additionally, 146 tanks were mapped (not shown in the table) in order to estimate the water quality, as described in the next subsection.

\subsection{Methodology: enhanced water point mapping}

The methodology used, EWPM, draws from the original WPM campaigns, including aspects promoted by the sanitary surveillance approach (Howard, 2002). In short, EWPM complements the original WPM campaign with three additional actions. First, basic water quality tests were carried out using portable water testing kits. The parameters measured include the so-called "critical parameters' (WHO, 1985; Howard, 2002): pH, turbidity, chlorine, electrical conductivity and concentration of faecal coliforms. The kit included a portable, battery-powered incubator. Thermotolerant (faecal) coliform counts could be obtained within 14-18 h of sampling giving a reliable indication of sanitary risk without the need for transport or laboratory facilities (University of Surrey, 2004). The acceptable threshold for the concentration of faecal coliforms used in our study was 10 colony-forming units (CFU)/100 ml of water. This value is significantly higher than WHO guidelines, which recommend $0 \mathrm{CFU} / 100 \mathrm{ml}$; however, it is a commonly used threshold to indicate high risk for human health in rural supplies in the context studied. As the WHO recognises, each country needs to take account of a variety of environmental, social, cultural, economic and other factors to define its standards of quality, which can be upgraded from time to time (WHO, 2008). The acceptable thresholds for other parameters were as follows: 30 NTU (nephelometric turbidity units) 
for turbidity, $1,000 \mu \mathrm{S} \mathrm{cm}^{-1}$ for electrical conductivity and $\mathrm{pH}$ values between 6.5 and 9.5 , in accordance with Tanzanian temporary standards.

Second, the year-round continuity of the water service was assessed by means of direct questions to users. The person responsible for each water point was contacted directly. A water point was not considered to be functional year round if the water users reported an interruption in service of more than one month in the dry season. This parameter helped to identify systems with a permanent lack of resources in the dry season.

Third, the perception of quality among users was assessed. Perceptions of water as being 'clear', 'coloured' or 'salty' were contrasted with the results of quality tests at the same water point. A 'clear' response was associated with satisfaction in the quality of water received, while 'coloured' and 'salty' indicated some suspicions or dissatisfaction with the water quality. Other quality perceptions (bad smell, fluoride) were not analysed; they were quite infrequent and could not be correlated with the parameters tested. Based on these criteria, quality perception was contrasted in 666 of the 692 tests performed.

\subsection{Sampling of quality measurements}

The methodology used was designed to provide a low-cost estimate of the effects that the consideration of the quality and year-round functionality of water points can have on coverage figures. To this end, quality measurements were taken according to the following criteria:

- For individual water points, quality tests were conducted in all cases.

- Networks were examined at one or two distribution points, depending on the network's size. When it was accessible, samples were also taken at the tank.

The initial assumption (which was confirmed by the results) was that small rural networks are mainly contaminated at the source, with much less contamination occurring in the distribution networks. Hence, the results of the analyses of the tank and distribution points were then compared and if the results were concordant (differences did not change the quality from acceptable to unacceptable or vice versa), the bacteriological quality of all water points in that network was deemed to be the same as that measured at the tank. If the results were contradictory, one of the following two solutions was adopted:

1. If only two measurements were available, the poorest result was used as the quality of the water delivered (this was the case in 7 of the 105 networks);

2. when more than two measurements were available, the predominant result (acceptable or not acceptable) was taken as the valid one ( 3 out of 105 networks fell into this category).

Table 2 shows the number of valid tests obtained per network. At least one valid quality test was obtained for each of the 105 networks analysed. In 36 cases, corresponding mostly to small networks with fewer than 10 water points (average size 6.17 functional water points per network), one valid test was performed. In the other 69 cases (51 plus 18, see Table 2), more than two tests were performed, depending on the size of the network.

The methodology followed a pattern of one test per 10 functional water points. Normally, the total number of functional water points per system was not known beforehand and, thus, the quality test 
Table 2. Quality tests at water points belonging to networks.

\begin{tabular}{lrrcc}
\hline Quality testing by network & $N$ & Percentage & Average number of functional WPs & Standard deviation \\
\hline Total networks analysed & 105 & & 10.10 & 8.38 \\
Networks with no valid quality tests & 0 & 0.0 & - & - \\
Networks with one valid quality test & 36 & 34.3 & 6.17 & 7.41 \\
Networks with two valid quality tests & 51 & 48.6 & 10.49 & 7.40 \\
Networks with three or more valid quality tests & 18 & 17.1 & 16.89 & 8.59 \\
\hline
\end{tabular}

campaign could not be planned exactly and some decisions had to be taken on the spot. This explains the relatively high standard deviation of the average size of networks with the same number of tests (right column). This incertitude ended up increasing the number of tests implemented in most cases. Of the 105 networks studied, a single valid test was performed for systems with more than 10 functional distribution points in only three cases.

In $59(85 \%)$ of the 69 cases for which more than one test was available, our hypothesis proved to be right: the faecal contamination of the tank was similar to that of the water points or, when the comparison was performed between two water points, no significant difference was found in faecal contamination (differences did not change the quality from acceptable to unacceptable or vice versa). This methodology made it possible to estimate the quality of the water delivered at all water points in each district and, thus, the coverage of bacteriologically acceptable water points, as described in Section 4.1.

\subsection{Coverage of the study}

In total, 3,363 water points offering water suitable for human consumption and 146 tanks were surveyed during 111 fieldwork days and 692 valid quality tests were performed. The area of study spanned more than $32,000 \mathrm{~km}^{2}$ and the rural districts involved had a total population of around 1.1 million people. Figure 1 gives the location of the districts surveyed. Table 3 shows the main data from the survey. As can be seen, the fewest quality tests were performed in Kigoma, despite the fact that it is the most populated of the three districts and the one with the most water points. This was because almost all functional water points belonged to relatively large networks, in which the same infrastructure was used to serve up to seven villages.

Table 4 shows the percentage of all functional water points tested. Only valid tests were included in the results, that is, those samples that were ultimately analysed and for which results were obtained (i.e. samples that were not altered, lost or damaged during collection or transport).

As mentioned above, water points belonging to networks (both gravity-fed and motorised) were tested at a rate of one or two per network and complemented with data from tanks. This accounts for the fact that, on average, only $12 \%$ were tested (173 tests for gravity-fed networks and 6 for motorised ones; see Table 4), together with $98 \%$ of the tanks. The 'other' category likewise has a low percentage of tested water points $(29 \%)$. This is because most of the water points in this category were rainwater-fed. In all three districts, the survey was carried out in the dry season and many of the water points, though operational, had no water at the time of the survey and hence their quality could only be measured in a few cases. In contrast, valid quality tests were obtained for $87 \%$ of functional isolated water points, that is, water points not belonging to networks. 


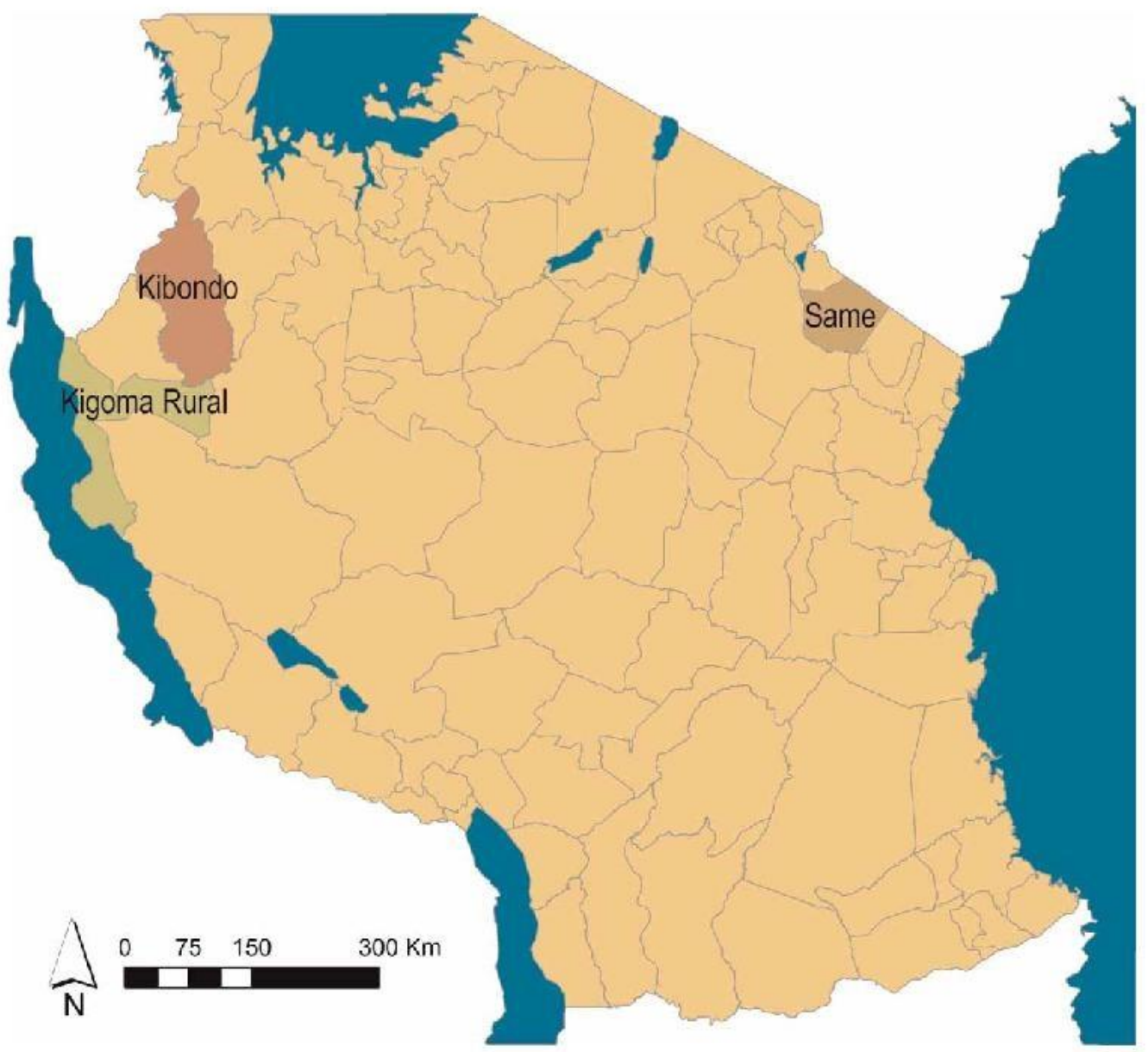

Fig. 1 Location of the districts surveyed.

Table 3. Main characteristics of the districts studied.

\begin{tabular}{lllll}
\hline & Same & Kigoma & Kibondo & Total \\
\hline Fieldwork days & 29 & 40 & 42 & 111 \\
Estimated area $\left(\mathrm{km}^{2}\right)$ & 5,186 & $11,545^{\mathrm{a}}$ & 16,058 & 32,789 \\
Estimated rural population at time of survey & 214,502 & 624,092 & 261,120 & $1,099,714$ \\
WPs effectively assessed for human consumption & 617 & 1,759 & 987 & 3,363 \\
Number of valid quality tests & 135 & 112 & 445 & 692 \\
\hline
\end{tabular}

a Only land surface was considered. Part of Kigoma's land is covered by Lake Tanganyika.

\subsection{Definitions}

An improved community water point (ICWP) is a place where water is drawn for various uses, such as drinking, washing and cooking and that has some improved facilities (Stoupy \& Sugden, 2003). An 
Table 4. Percentage of functional water points for which valid tests were obtained in the study.

\begin{tabular}{llccl}
\hline WP category & Belongs to network & Functional WPs & $\begin{array}{l}\text { Number of } \\
\text { valid tests }\end{array}$ & $\begin{array}{l}\text { \% of functional } \\
\text { WPs tested }\end{array}$ \\
\hline Deep wells/BHs with hand pump & No & 89 & 70 & 78.7 \\
Shallow wells with hand pump & No & 172 & 146 & 84.9 \\
Gravity-fed & Yes & 1,543 & 173 & $11.2^{\mathrm{a}}$ \\
Protected springs & No & 233 & 213 & 91.4 \\
Motorised water points & Yes & 10 & 6 & $60.0^{\mathrm{a}}$ \\
Other & Mixed & 79 & 23 & 29.1 \\
Tanks & Yes & 62 & 61 & 98.4 \\
\hline
\end{tabular}

${ }^{a}$ Not all water points belonging to networks were tested, as explained in the main text.

improved drinking water source is one that by the nature of its construction adequately protects the source from outside contamination, in particular with faecal matter (WHO/UNICEF, 2000). Access is normally defined by establishing a ratio between the number of people served by each water point and the maximum distance travelled by users to reach it. In Tanzania, this ratio is one water point per 250 people within a radius of $400 \mathrm{~m}$ (GoT, 2002). In order to assess accurately the number of people served using distance as a criterion, it is necessary to know the spatial distribution of households and this can be problematic in many cases. On the other hand, thanks to the existence of periodic sociological censuses, the number of inhabitants belonging to each administrative structure is usually quite well documented. Considering the limited precision of assessments based on the spatial distribution of households, we measured access in terms of the number of people served per water point (250), regardless of whether their households were located more than $400 \mathrm{~m}$ away from the water point.

Hence, the first indicator of access is improved community water point density (IWPD), which is equal to the number of ICWPs per 1,000 inhabitants. In Tanzania, an area would be considered to have access if its density is four or more water points per 1,000 inhabitants and the percentage of people not served in an area would be proportional to the lack of available water points based on that threshold. However, the survey also assessed the functionality of each water point and this information was included in the definition of access. Consequently, functional community water point density (FWPD) is frequently used as the access indicator.

By including quality and seasonality information, EWPM allows for the definition of further indicators. Bacteriologically acceptable functional community water point density (BAFD) is defined as the number of functional community water points per 1,000 inhabitants that provide water with an acceptable concentration of faecal coliforms at the time of the test (less than $10 \mathrm{CFU} / 100 \mathrm{ml}$ in our study).

A water point is not considered to be functional year round if water users report a seasonal interruption in the supply of more than one month. Taking this concept into account, year-round functional community water point density (YRFD) is defined as the number of functional community water points per 1,000 inhabitants that work at least 11 months per year. These last two concepts can be combined in the indicator 'bacteriologically acceptable and year-round functional water point density' (BA\&YRFD), which measures the coverage by water points that provide acceptable water quality and were functional year round at the time of the test. 


\section{Results}

\subsection{Quality test results by water point category}

Table 5 shows the results of the quality tests. The most important risk was the presence of total coliforms, which affected $22.0 \%$ of the water points studied. By category, $31.0 \%$ of cases in 'other' had faecal contamination. This is due to the elevated number of improved wells without hand pumps that were tested in this category. Gravity-fed water points were the next most affected $(26.0 \%)$ and, remarkably, significant faecal contamination was found in $19.7 \%$ of the examined tanks. More than $21 \%$ of the water points in protected springs and shallow wells were highly contaminated, while deep wells performed best in this regard.

$\mathrm{pH}$ was the second most recurrent parameter, affecting the quality of water in $9.2 \%$ of the cases. Moreover, $94 \%$ of all cases with a low $\mathrm{pH}$ were found in one district, Kigoma. There, an acidic $\mathrm{pH}$ affected $53 \%$ of the water points tested in the district, including $75 \%$ of the hand pumps. Low pH in itself is not a health concern, but acidic water could contain metal ions. No conclusions could be drawn regarding the reasons behind this finding based on the available data. A comprehensive sampling campaign together with soil composition tests should be carried out to clarify this aspect.

Turbidity was likewise only relevant in the Kigoma district, as it is mostly served by surface water and shallow wells. There, $33 \%$ of the shallow wells and $10 \%$ of the gravity-fed water points had values over 30 NTU. Altogether, high turbidity affected $5.2 \%$ of the water points tested. Electrical conductivity values greater than $1,000 \mu \mathrm{S} \mathrm{cm}^{-1}$ were only found for hand pumps. This parameter was only significant in Same, where $71 \%$ of the deep wells exceeded this threshold. None of the water points had a value greater than $2,000 \mu \mathrm{S} \mathrm{cm}^{-1}$. In total, high conductivity affected $2.0 \%$ of the studied water points. Chlorine was not a significant parameter in the study, since chlorination is not done regularly in any of the rural systems studied.

\subsection{Perceived vs. measured quality}

Table 6 shows the results for perceived versus measured quality, contrasted in 666 of the 692 tests performed. From those cases, most water was described as 'clear' by users $(N=621)$. Of these

Table 5. Results of the quality tests by water point category.

\begin{tabular}{|c|c|c|c|c|c|}
\hline Category & $\begin{array}{l}\text { Complete test } \\
(n)\end{array}$ & $\begin{array}{l}\text { Total coliforms } \\
(>10 \mathrm{CFU} / 100 \mathrm{ml})(\%)\end{array}$ & $\begin{array}{l}\text { Turbidity } \\
(>30 \text { NTU })(\%)\end{array}$ & $\begin{array}{l}\mathrm{EC} \\
\left(>1,000 \mu \mathrm{S} \mathrm{cm}^{-1}\right)(\%)\end{array}$ & $\begin{array}{l}\mathrm{pH}(<6.5 \text { or } \\
>9.5)(\%)\end{array}$ \\
\hline $\begin{array}{l}\text { Deep wells/BHs with } \\
\text { hand pump }\end{array}$ & 70 & 12.9 & 8.6 & 10.0 & 1.4 \\
\hline $\begin{array}{l}\text { Shallow wells with } \\
\text { hand pump }\end{array}$ & 146 & 21.9 & 6.8 & 2.7 & 7.5 \\
\hline Gravity-fed & 173 & 26.0 & 6.9 & 0.6 & 20.8 \\
\hline Protected springs & 213 & 21.1 & 0.5 & 0.0 & 5.6 \\
\hline Other & 29 & 31.0 & 3.4 & 3.4 & 0.0 \\
\hline Tanks & 61 & 19.7 & 9.8 & 1.6 & 6.6 \\
\hline Total & 692 & 22.0 & 5.2 & 2.0 & 9.2 \\
\hline
\end{tabular}


Table 6. Relationship between measured water quality and users' reported opinions.

\begin{tabular}{|c|c|c|c|c|}
\hline \multicolumn{2}{|c|}{ Quality reported by users } & \multicolumn{3}{|l|}{ Quality measured } \\
\hline Opinion & $N$ & $\begin{array}{l}\% \text { with acceptable total } \\
\text { coliforms }\end{array}$ & $\begin{array}{l}\% \text { with acceptable } \\
\text { turbidity }\end{array}$ & $\begin{array}{l}\% \text { with acceptable electrical } \\
\text { conductivity }\end{array}$ \\
\hline Clear & 621 & 78.6 & 96.6 & n.a. \\
\hline Coloured & 16 & 75.0 & 31.3 & n.a. \\
\hline Salty & 29 & n.a. & n.a. & 31.0 \\
\hline
\end{tabular}

cases, $78.6 \%$ had acceptable values of microbiological water quality. That means that over $20 \%$ of water points labelled as 'clear' posed a significant risk to human health. In $96.6 \%$ of the cases, the turbidity level was less than 30 NTU. This is not surprising, since turbidity is directly observable at high values. Coloured water was reported only 16 times; of these, only $31.3 \%$ had acceptable turbidity and $75.0 \%$ less than $10 \mathrm{CFU} / 100 \mathrm{ml}$. Of the reported cases of salinity $(N=29)$, only $31.03 \%$ had electrical conductivity values greater than $1,000 \mu \mathrm{S} \mathrm{cm}{ }^{-1}$.

In conclusion, apart from parameters directly related to water's appearance, users' perceptions of quality did not provide reliable information about actual water quality. Hence, users' perceptions are mostly useful in determining their satisfaction with and acceptance of the water they have and not as an indicator of water quality.

\subsection{Year-round continuity of supply}

Table 7 shows the results of the year-round continuity of the supplies. In general terms, the seasonality of supplies affected $19.0 \%$ of water points. By category, 'other' was the most seasonal, mostly due to rainwater-fed water points. Gravity-fed water points were seasonal in $19.5 \%$ of the cases, followed by shallow wells $(9.9 \%)$. As expected, the water point category least prone to seasonality was 'deep wells/ boreholes' $(6.7 \%)$.

By district, seasonality was most acute in Same (31.1\% of the water points). An intermediate value was found in Kigoma (18.6\%) and the lowest value in Kibondo (12.6\%). This was expected, since Same belongs to the arid north-eastern part of the country and is known to be vulnerable to droughts (Quinn et al., 2003; The Guardian, 2006, 2009).

Table 7. Results of water point seasonality by category.

\begin{tabular}{lccc}
\hline WP category & Functional WPs & Seasonal WPs & Percentage \\
\hline Deep wells/BHs with hand pump & 89 & 6 & 6.7 \\
Shallow wells with hand pump & 172 & 17 & 9.9 \\
Gravity-fed & 1,543 & 301 & 19.5 \\
Protected springs & 233 & 11 & 4.7 \\
Other & 89 & 68 & 76.4 \\
Total WPs & 2,126 & 403 & 19.0 \\
\hline
\end{tabular}




\section{Discussion}

\subsection{Estimated coverage, including quality and year-round continuity of supply}

The results of the quality analysis were extrapolated to all water points in the area of study in accordance with the definitions of water point density and the methodology explained in Section 2 . Table 8 shows the results for the three districts studied. Historically, Kigoma has received poorer attention, with the existing water points covering just $46.7 \%$ of the estimated 2008 population, compared to $65.1 \%$ in Same and $76.7 \%$ in Kibondo. The effects of the distribution and functionality of water points were very similar in all three cases, with an average reduction of $30 \%$ owing to non-functionality, bringing coverage down to $43.4 \%$ in Same, $31.8 \%$ in Kigoma and $57.0 \%$ in Kibondo.

The effect of bacteriological contamination on functional water points was also very similar in all cases (see values in brackets in the table). Coverage fell by an average of $26 \%$ when the presence of coliforms was considered, dropping to $33.2 \%$ in Same, $23.4 \%$ in Kigoma and $41.1 \%$ in Kibondo. The effect of seasonality was more variable and depended on the climatic conditions, as expected, with an average reduction of $18 \%$. When the quality and seasonality factors were combined, coverage fell by $40 \%$ on average. Values range from a $32 \%$ reduction in Kibondo to a $45 \%$ reduction in Kigoma, reflecting the influence of different technology and climatic conditions. All these coverage figures are significantly lower than those reported by the Tanzanian Ministry of Water, as seen in the first row of Table 8.

The mapping methodology also gives the possibility of representing data in a visual way (Jiménez \& Pérez-Foguet, 2008), which has been widely used by several social organisations in different contexts to promote awareness at various levels (Jiménez et al., 2009).

\subsection{Results of similar studies}

RADWQ results from UNICEF also show significant quality problems in rural water points, although results vary significantly by technology and country. For example, in Ethiopia, $23.10 \%$ of the 290 boreholes tested had more than $10 \mathrm{CFU} / 100 \mathrm{ml}$ of water, together with $34.20 \%$ of the 155 protected dug

Table 8. Access to water by district analysed according to different parameters: existence of improved water points (IWPD), functionality (FWPD), bacteriological quality (BAFD), year-round functionality (YRFD) and the combination of bacteriological quality and year-round functionality (BA\&YRFD).

\begin{tabular}{lllll}
\hline & & & & $\begin{array}{l}\text { Mean \% reduction in functional } \\
\text { WP coverage (individual \% } \\
\text { in brackets) }\end{array}$ \\
\hline Coverage reported by GoT (GoT, 2008) & 51.0 & 51.8 & 60.0 & - \\
Improved WP density & 65.1 & 46.7 & 76.7 & - \\
$\begin{array}{l}\text { Functional improved WP density } \\
\text { Bacteriological acceptable functional }\end{array}$ & 43.4 & 31.7 & 57.0 & - \\
$\quad 33.2$ & 23.4 & 41.1 & $26(24,26,28)$ \\
$\quad$ WP density & & & & $18(27,19,9)$ \\
Year round functional WP density & 31.8 & 25.8 & 51.6 & $40(43,45,32)$ \\
Bacteriological acceptable \& year & 24.9 & 17.5 & 38.9 & \\
$\quad$ round functional WP density & & & &
\end{tabular}


wells tested and $46.80 \%$ of the 319 protected springs (WHO/UNICEF, 2010c). Results for Nigeria show that only $1 \%$ of the 525 boreholes tested but $33 \%$ of the 424 protected wells had values of more than $10 \mathrm{CFU} / 100 \mathrm{ml}$ (WHO/UNICEF, 2010e).

Looking at people's perception of quality, a study conducted on 376 boreholes in four districts of Zimbabwe (Hoko, 2005) showed no clear correlation between measured parameters and people's perception of quality. This applied to the relationship between observed unsatisfactory colour and measured turbidity, as well as to the relationship between complaints about taste and measured electrical conductivity.

With regard to year-round continuity of supply, in another study of 144 water points in Zimbabwe (Hoko \& Hertle, 2006), users reported seasonality rates of 65, 72, 21 and 29\% in four different districts, with great variation from place to place.

\subsection{The costs of measuring quality}

The cost of this methodology is around US\$12-15/water point for a standard WPM campaign (Stoupy \& Sugden 2003) and around US\$20/water point when quality analysis is included with the methodology proposed, that is, analysing all individual points and conducting a small number of tests in networks. The initial investment in the water kit is not included in this estimate. While this cost may appear high, it is not so expensive in light of the significant investments projected to be made in the sector. About US\$2 million would be needed for data collection in Tanzania, for example, while the sector was projected to receive US\$950 million in investments from 2007 to 2011 . Moreover, the whole process, including quality measurements, may cost considerably less if the methodology is scaled up. Including quality tests in a standard WPM campaign or other monitoring tasks significantly reduces the cost. As WPM may be adopted in Tanzania as a monitoring methodology, this is a relevant fact. The latest RADWQ data on ad hoc quality testing campaigns show a cost of US\$50-72/sample (Properzi, 2010).

\subsection{Basic quality testing as a starting point for water safety plans}

The development of water safety plans for small systems should focus on the control of microbial quality and, in particular, pathogens derived from faecal contamination (WHO, 2005). We acknowledge that the measurements undertaken are very basic (in both frequency and scope) for the purpose of drawing conclusions on the quality of the water delivered. They should instead be considered as a starting point to understand the situation in each village and identify the places at greatest risk. Communities are unlikely to have the necessary skills to develop system-specific water safety plans without outside assistance (WHO, 2005), especially for piped systems; however, our results for community piped systems show a high incidence of quality-related problems. Hence, the approach proposed is to use the results to involve district authorities in the solution of water quality problems. Villages can be prioritised in the district planning, both for the improvement of water quality and to increase the reliability of service, as explained elsewhere (Jiménez \& Pérez-Foguet, 2010). The responsibility of the corresponding local authorities is increased, which is of utmost importance in implementing any action related to quality surveillance and control. 


\section{Conclusions}

Ensuring the delivery of a water supply with acceptable quality is a major challenge, especially in rural areas of developing countries. Despite being included in the definition of the MDG target (sustainable access to safe drinking water) and having long been recognised as a key aspect by the WHO, this factor is not included in the JMP's measurements owing to the technical and logistical difficulties involved and its high cost (WHO/UNICEF (2010a)). The current focus on HWT has probably drawn some attention away from this problem by shifting the responsibility (and costs) of safe water to the end users.

This study has presented a methodology to estimate the incidence of poor quality in rural water at a reduced cost. The results offer some insights into the relationship between access to improved water sources, the quality of the water delivered and year-round continuity of the services, broken down by technology. When the results were assimilated into the relevant networks, access figures fell by $26 \%$ when the presence of coliforms was considered and by $18 \%$ when year-round continuity of service was considered. When the quality and seasonality aspects were combined, coverage figures dropped $40 \%$ for the districts studied compared to the coverage figures reflecting just functionality. Hence, the water services provided by two out of five improved water points in the rural areas studied can be expected to have either quality or seasonality-related problems. This fact is currently being ignored at all decision-making levels in water policy, since the available indicators do not capture it. No action is being taken to correct this situation, which has a significant impact on the health and well-being of millions of people.

Including simple quality and seasonality measurements in routine data collection, as presented here, is a necessary step towards addressing the problem. They can serve as a starting point to help local governments identify those places at greatest risk and address future challenges, starting with the most critical points. Risk assessment at the places most at risk can help to determine the initial actions to be promoted from the local government level. Otherwise, the immense nature of the duty as a whole might prevent governments from acting.

\section{Acknowledgements}

The author/s would like to thank ONGAWA, formerly Ingeniería sin Fronteras-Asociación para el Desarrollo (ISF-ApD), and Universitat Politècnica de Catalunya for their support in undertaking the mapping project and WaterAid Tanzania for the data and assistance provided. They would also like to acknowledge the research grants provided by the UPC-CCD 2009 and the ACCD U2008. Thanks are also given to ONGAWA staff and volunteers in Tanzania, especially to Gema Mico, Angel Fernández, Sergio Verdejo, Carles Pol and Nuria Baqués, for their dedicated work during and after the mapping surveys, and to Ricard Giné for his useful comments on earlier versions of this paper. Finally, the authors are grateful to the Same, Kigoma and Kibondo District Water Departments for their collaboration.

\section{References}

Ahmad, J., Goldar, B. \& Misra, S. (2005). Value of arsenic-free drinking water to rural households in Bangladesh. Journal of Environmental Management 74, 173-185.

Bartram, J. (2008). Improving on have and have-nots. Commentary. Nature 452, 283-284. 
Esrey, S. A., Potash, J. B., Roberts, L. \& Shiff, C. (1991). Effects of improved water supply and sanitation on ascariasis, diarrhoea, dracunculiasis, hookworm infection, schistosomiasis and trachoma. Bulletin World Health Organization 69 (5), $609-621$.

Fay, M., Leipziger, D., Wodon, Q. \& Yepes, T. (2005). Achieving child-health-related millennium development goals: the role of infrastructure. World Development 33(8), 1267-1284.

Fewtrell, L., Kaufmann, R. B., Kay, D., Enanoria, W., Haller, L. \& Colford, J. M. (2005). Water, sanitation and hygiene interventions to reduce diarrhoea in less developed countries: a systematic review and meta-analysis. Lancet Infection Disease $5(1), 42-52$.

Government of United Republic of Tanzania (2002). National Water Policy. Ministry of Water and Livestock Development, Dar es Salaam.

Government of United Republic of Tanzania (2008). Water Sector Performance Report for the year 2007/2008. Ministry of Water and Irrigation, October 2008, 81.

Hoko, Z. (2005). An assessment of the water quality of drinking water in rural districts in Zimbabwe: the case of Gokwe South, Nkayi, Lupane and Mwenezi districts. Physics and Chemistry of the Earth 30, 859-866.

Hoko, Z. \& Hertle, J. (2006). An evaluation of the sustainability of a rural water rehabilitation project in Zimbabwe. Physics and Chemistry of the Earth 31, 699-706.

Howard, A. (2002). Water Quality Surveillance: A practical guide. WEDC, Loughborough University, UK. Available at: http:// www.lboro.ac.uk/watermark/practical-guide/wqs-insides.pdf (accessed 19 January 2012).

Hunt, C. (2001). How Safe is Safe? A concise review of the health impacts of water supply, sanitation and hygiene. WELL Study No. 509. WELL Resource Centre (WEDC \& LSHTM), London and Loughborough.

Hunter, P. R., Pond, K., Jagals, P. \& Cameron, J. (2009a). An assessment of the costs and benefits of interventions aimed at improving rural community water supplies in developed countries. Science of the Total Environment 407, 3681-3685.

Hunter, P. R., Zmirou-Navier, D. \& Hartemann, P. (2009b). Estimating the impact on health of poor reliability of drinking water interventions in developing countries. Science of the Total Environment 407, 2621-2624.

Hunter, P. R., MacDonald, A. M. \& Carter, R. C. (2010). Water supply and health. PLoSMed 7(11), e1000361.

Jawahar, P. \& Ringler, C. (2009). Water quality and food safety: a review and discussion of risks. Water Policy 11(6), 680-695.

Jiménez, A. \& Pérez-Foguet, A. (2008). Improving water access indicators in developing countries: a proposal using water point mapping methodology. Water Science and Technology: Water Supply-WSTWS 8(3), 279-287.

Jiménez, A. \& Pérez-Foguet, A. (2010). Building the role of local government authorities towards the achievement of the right to water in rural Tanzania. Natural Resources Forum 34, 93-105.

Jiménez, A. \& Pérez-Foguet, A. (2011). The relationship between technology and functionality of rural water points: evidence from Tanzania. Water Science and Technology 63(5), 949-956.

Jiménez, A., Muñoz, D., Pérez-Foguet, A., Pascual, J. \& Verdejo, S. (2009). Aplicaciones de SIG en programas de desarrollo: Experiencia de ISF-ApD en Tanzania. Cuadernos de Tecnología para el Desarrollo Humano, 08. Ingeniería Sin Fronteras.. Available at http://www.cuadernos.tpdh.org/file_upload/08_TIG_10_tanzania.pdf (accessed 19 January 2012).

Johnson, D. M., Hokanson, D. R., Zhang, Q., Czupinski, K. D. \& Tang, J. (2008). Feasibility of water purification technology in rural areas of developing countries. Journal of Environmental Management 88, 416-427.

Kumar Biswas, P. \& Mandal, K. (2010). Drinking water in rural India: a study of deficiency, quality and some social implications. Water Policy 12(6), 885-897.

Luby, S. P., Mendoza, C., Keswick, B. H., Chiller, T. M. \& Hoekstra, R. M. (2008). Difficulties in bringing point-of-use water treatment to scale in rural Guatemala. American Journal of Tropical Medicine and Hygiene 78(3), 382-387.

Masduqi, A., Endah, N., Soedjono, E. S. \& Hadi, W. (2010). Structural equation modeling for assessing the sustainability of rural water supply systems. Water Science and Technology: Water Supply 10(5), 815-823.

Paavola, J. (2008). Livelihoods, vulnerability and adaptation to climate change in Morogoro, Tanzania. Environmental Science \& Policy 11, 642-654.

Properzi, F. (2010). Rapid Assessment of Drinking-Water Quality. World Health Organization, Presentation at the 2010 Stockholm International Water Week.

Quinn, C. H., Huby, M., Kiwasila, H. \& Lovett, J. C. (2003). Local perceptions of risk to livelihood in semi-arid Tanzania. Journal of Environmental Management 68, 111-119.

Reimann, C. \& Banks, D. (2004). Setting action levels for drinking water: are we protecting our health or our economy (or our backs!)? Science of the Total Environment 332, 13-21. 
Rietveld, L. C., Haarhoff, J. \& Jagals, P. (2009). A tool for technical assessment of rural water supply systems in South Africa. Physics and Chemistry of the Earth 34, 43-49.

Schmidt, W. \& Cairncross, S. (2009). Household water treatment in poor populations: is there enough evidence for scaling up now? Environmental Science and Technology 43(4), 986-992.

Stoupy, O. \& Sugden, S. (2003). Halving the Number of People without Access to Safe Water by 2015 - A Malawian Perspective. Part 2: New indicators for the millennium development goal. WaterAid.

Sutton, S. (2008). The risks of a technology-based MDG indicator for rural water supply. In 33rd WEDC Conference Proceedings, Accra, Ghana.

The Guardian (2006). Starving Villagers in Same Survive on Wild Fruits. The Guardian. By Patrick Kisembo, Ndungu. Published on 27 February 2006.

The Guardian (2009). Tough Time Ahead as Food Shortage Looms. The Guardian. By Polycarp Machira. Published on 16 August 2009.

United Nations (2002). General Comment No. 15. U.N. Doc. E/C.12/2002/11. Economic Social Cultural Rights Committee.

University of Surrey (2004). Oxfam- Del Agua Portable Water Testing Kit User's Manual. Version 4.1, Robens Centre for Public and Environmental Health, University of Surrey.

Vasquez, W. F., Mozumder, P., Hernández-Arce, J. \& Berrens, R. P. (2009). Willingness to pay for safe drinking water: evidence from Parral, Mexico. Journal of Environmental Management 90, 3391-3400.

WaterAid (2010). Water point mapping in East Africa. Based on a strategic review of Ethiopia, Tanzania, Kenya and Uganda. WaterAid.

WaterAid, Overseas Development Institute (2005). Learning for Advocacy and Good Practice-WaterAid water point mapping. Overseas Development Institute, Katharina Welle. Available at: http://www.wateraid.org/international/what_we_do/policy_and_research/ (accessed 19 January 2012).

World Health Organization (1985). Guidelines for Drinking Water Quality, 2nd edition, Vol. III, World Health Organization Press, Geneva.

World Health Organization (2005). Water Safety Plans. Managing drinking-water quality from catchment to consumer. World Health Organization Press, Geneva.

World Health Organization (2006). Core Questions on Drinking-Water and Sanitation for Household Surveys. World Health Organization and UNICEF, p. 8. Available at: http://www.who.int/water_sanitation_health/monitoring/household_surveys/ en/index.html (accessed 19 January 2012).

World Health Organization (2008). Guidelines for Drinking-water Quality, 3rd edition, World Health Organization, Geneva.

WHO/UNICEF (2000). Global Water Supply and Sanitation Assessment Report. WHO/UNICEF Joint Monitoring Programme for Water Supply and Sanitation. World Health Organization Press, Geneva.

WHO/UNICEF (2010a). Progress on sanitation and drinking-water. 2010 Update. Joint Monitoring Programme for Water Supply and Sanitation. World Health Organization Press, Geneva.

WHO/UNICEF (2010b). Rapid assessment of Drinking-Water Quality in the Hashemite Kingdom of Jordan. Available at: http://www.wssinfo.org/documents-links/documents/?tx_displaycontroller[type]=water_quality_reports (accessed 19 January 2012).

WHO/UNICEF (2010c). Rapid Assessment of Drinking-Water Quality in the Federal Democratic Republic of Ethiopia. Country Report. Available at: http://www.wssinfo.org/documents-links/documents/?tx_displaycontroller[type]=water_quality_ reports (accessed 19 January 2012).

WHO/UNICEF (2010d). Rapid Assessment of Drinking-Water Quality in the Republic of Nicaragua. Country Report. Available at: http://www.wssinfo.org/documents-links/documents/?tx_displaycontroller[type]=water_quality_reports (accessed 19 January 2012).

WHO/UNICEF (2010e). Rapid Assessment of Drinking-Water Quality in the Federal Republic of Nigeria. Country Report. Available at: http://www.wssinfo.org/documents-links/documents/?tx_displaycontroller[type]=water_quality_reports (accessed 19 January 2012).

WHO/UNICEF (2010f). Rapid Assessment of Drinking-Water Quality in the Republic of Tajikistan. Country Report. Available at: http://www.wssinfo.org/documents-links/documents/?tx_displaycontroller[type]=water_quality_reports (accessed 19 January 2012).

Received 14 February 2011; accepted in revised form 29 August 2011. Available online 31 December 2011 